\title{
PERANAN INTENSITAS NYERI TERHADAP ASPEK PSIKOLOGIS PENDERITA NYERI NEUROMUSKULOSKELETAL KRONIS NON KANKER RUMAH SAKIT ATMA JAYA
}

\author{
Hendro Saulata, ${ }^{1}$ Jimmy Barus $^{2}$, Surilena ${ }^{3}$
}

\author{
${ }^{1}$ Program Studi Pendidikan Dokter, FKIK Unika Atma Jaya, Jakarta, Indonesia \\ ${ }^{2}$ Departemen Neurologi, FKIK Unika Atma Jaya, Jakarta, Indonesia \\ ${ }^{3}$ Departemen Ilmu Kedokteran Jiwa dan Perilaku, FKIK Unika Atma Jaya, Jakarta, Indonesia
}

Diterima 18 Juni 2018

Disetujui 29 April 2019

Publikasi 27 Mei 2019

Korespondensi: hendrosaulata@yahoo.com
Cara merujuk artikel ini: Saulata (et al). 2019. Peranan Intensitas Nyeri Terhadap Aspek Psikologis Penderita Nyeri Neuromuskuloskeletal Kronis Non Kanker Rumah Sakit Atma Jaya. Callosum Neurology Journal 2(2): 49-57. DOI: https://doi/org/10.29342/cnj.v2i2.23

\begin{abstract}
ABSTRAK
Latar Belakang: Nyeri kronis dapat menimbulkan dampak psikologis (depresi, cemas, dan stres) yang memengaruhi kualitas hidup. Gangguan mental juga dapat memperburuk intensitas nyeri sehingga berdampak pada luaran terapi.

Tujuan: Mendapatkan hubungan antara intensitas nyeri dengan depresi, cemas, dan stres pada penderita nyeri neuromuskuloskeletal kronis di RS Atma Jaya Jakarta.

Metode: Desain penelitian deskriptif analitik dengan data sekunder dari Pain Registry. Instrumen penelitian adalah kuesioner demografi, intensitas nyeri, dan DASS (Depression Anxiety Stress Scale).
\end{abstract}

Hasil: 85 penderita nyeri neuromuskuloskeletal kronis menunjukkan $63,5 \%$ depresi, 78,8\% cemas, dan $70,6 \%$ stres. Terdapat hubungan bermakna antara usia dan depresi $(\mathrm{p}=0,01)$, cemas $(\mathrm{p}=0,04)$, serta IN1 $(\mathrm{p}=0,00)$ dengan kejadian depresi, IN1 $(\mathrm{p}=0,00)$ dan IN2 $(\mathrm{p}=0,01)$ dengan kecemasan, dan IN1 dengan stres $(\mathrm{p}=0,04)$.

Simpulan: Terdapat hubungan antara berbagai kategori intensitas nyeri terhadap kondisi depresi, cemas, dan stres pasien dengan nyeri neuromuskuloskeletal kronis.

Kata Kunci: nyeri neuromuskuloskeletal, intensitas nyeri, aspek psikologis

\begin{abstract}
Background: Chronic pain has psychological impact (depression, anxiety, and stress) which may affect patient's quality of life. Mental disorders can also aggravate the pain intensity so affects treatment outcome.

Purpose: To determine the relationship between pain intensity with depression, anxiety, and stress in chronic neuromusculoskeletal pain at Atma Jaya Hospital Jakarta.

Method: This was a descriptive analytical study using secondary data from Pain Registry. Demographic and pain intensity questionnaire, DASS (Depression Anxiety Stress
\end{abstract} Scale) were used.
Result: 85 patients with chronic neuromusculosceletal pain of which $63.5 \%$ had depression, $78.8 \%$ anxiety, and $70.6 \%$ stress. There were significant relationship between age with depression $(\mathrm{p}=0.01)$ and anxiety $(\mathrm{p}=0.04)$, as well as between IN1 with depression $(\mathrm{p}=0.00)$;

Conclusion: There was an association of pain intensity among depression, anxiety, and stress condition in chronic neuromusculosceletal pain.

Keywords: neuromusculosceletal pain, Pain intensity, Depression, Anxiety, Stress. 


\section{Latar Belakang}

Nyeri adalah pengalaman sensorik dan emosional yang berhubungan dengan kerusakan jaringan atau stimulus yang potensial dapat menimbulkan kerusakan jaringan. Nyeri neuromuskuloskeletal adalah nyeri yang terjadi akibat kerusakan jaringan saraf, tulang, otot dan jaringan lain disekitarnya. Nyeri, berdasarkan durasinya dibagi menjadi nyeri akut dan nyeri kronis. Nyeri akut yang berlangsung kurang dari 3 bulan merupakan respons fisiologi tubuh yang menandakan adanya rangsangan nosiseptor. ${ }^{1}$ Nyeri kronis menetap selama 3-6 bulan, atau bahkan lebih, dapat dirasakan secara kontinu (background pain) atau intermiten (episodic pain) dan memiliki intensitas nyeri yang berbedabeda. $^{2}$

Individu dengan nyeri kronis memiliki dampak fisik, psikologi, dan sosial. Dampak fisik yang sering dijumpai adalah gangguan tidur, dampak sosial adalah terganggunya fungsi sosial, pekerjaan, dan kegiatan fisik penderita, sehingga memengaruhi kehidupan sosial penderita. ${ }^{6}$ Dampak psikologi yang umum terjadi adalah depresi, cemas, dan stres. Penelitian Rayner (2016) menunjukan $60,8 \%$ pasien nyeri kronis yang berobat ke spesialis nyeri memenuhi kriteria probable depression, dan $33,8 \%$ mengalami depresi berat. ${ }^{7}$ Penelitian Wong (2011) ansietas terjadi pada $23,2 \%$ pasien dengan nyeri kronis. ${ }^{8}$ Penelitian Sathya (2015) stres berat pada pasien nyeri punggung bawah terjadi pada $23,07 \%$ pada pasien usia lanjut dibanding $21,62 \%$ pada pasien dengan usia muda. ${ }^{9}$

Depresi dapat memperburuk proses pengobatan nyeri kronis, penderita merasa pesimis, tidak patuh berobat dan mengakibatkan nyeri semakin sulit diobati. ${ }^{10}$ Cemas membuat penderita semakin sensitif terhadap nyeri yang dirasakan. Stres dapat membuat kondisi tubuh penderita memburuk, sulit tidur dan menurunnya nafsu makan. Adanya masalah atau gangguan mental emosional dapat menyebabkan kualitas hidup penderita terganggu. De Heer (2014) menyatakan depresi, cemas, dan stres juga dapat memperburuk intensitas nyeri sehingga hal ini berdampak pada hasil penatalaksaan. ${ }^{11}$ Tujuan penelitian ini adalah mengukur hubungan antara intensitas nyeri dengan depresi, cemas, dan stres pada penderita nyeri neuromuskuloskeletal kronis di Rumah Sakit Atma Jaya Jakarta.

\section{Metode Penelitian}

Penelitian ini adalah penelitian deskriptif analitik potong lintang yang dilakukan pada poliklinik saraf Rumah Sakit Atma Jaya bulan Maret 2016 Agustus 2017. Sampel penelitian adalah total sampling dari seluruh pasien nyeri kronis non kanker di poliklinik saraf Rumah Sakit Atma Jaya bulan Maret 2016 - Agustus 2017 yang berjumlah 85 responden.

Intrumen yang digunakan dalam pengumpulan data adalah kuesioner demografi, kuesioner intensitas nyeri, dan kuesioner DASS (Depression Anxiety Stress Scale). Kuesioner demografi berisi usia, jenis kelamin, status pernikahan, pendidikan, dan pekerjaan. Kusioner intensitas nyeri memiliki skala $0-10$. Item pertanyaan adalah mengenai derajat intensitas nyeri saat ini, dan rata - rata intensitas nyeri dalam seminggu. Nilai 0 menandakan tidak nyeri dan nilai 10 menandakan sangat nyeri. Kuesioner DASS-42 berisi 42 pertanyaan untuk mengukur keadaan emosi seseorang, yaitu depresi, cemas, dan stres. Penilaian depresi berdasarkan total dari skor yang telah diisi, bila jumlah skor depresi 0 - 9 : Normal; $10-13$ : Ringan; $14-20$ : Sedang; $21-27$ : Berat; $>28$ : Sangat berat. Jumlah skor cemas $0-7$ : Normal; $8-9$ : Ringan; $10-14$ : Sedang; 15 - 19: Berat; $>20$ : Sangat berat. Jumlah skor stres 0 - 14 : Normal; 15 - 18 : Ringan; 19 25 : Sedang; 26 - 33 : Berat; $>34$ : Sangat berat. Ethical Clearance Committee, Faculty of Medicine, Atma Jaya Catholic University of Indonesia, 01/03/KEP-FKUAJ/2017- April 3, 2017.

\section{Hasil Penelitian}

Sebanyak 85 penderita nyeri neuromuskuloskeletal kronis dengan rentang usia $24-78$ tahun. Sebanyak $69,4 \%$ usia $<60$ tahun, $65,9 \%$ perempuan, $95,3 \%$ menikah, $35,3 \%$ pendidikan SD, $60 \%$ tidak bekerja (Tabel 1).

Penelitian ini menunjukan bahwa dari keseluruhan subjek $63,5 \%$ mengalami depresi, $78,8 \%$ cemas dan $70,6 \%$ stres. Tingkat depresi terbanyak adalah depresi sangat berat $(35,2 \%)$. Tingkat cemas yang terbanyak adalah cemas sangat berat $(46,2 \%)$ Tingkat stres terbanyak adalah stres berat (30\%). 
Tabel 1. Karakteristik demografi dan depresi, cemas, dan stres nyeri neuromuskuloskeletal kronis

Variabel

Frekuensi n(\%)

Usia

- $\quad<60$ tahun

$59(69,4) *$

- $\geq 60$ tahun

$26(30,6)$

Jenis kelamin

- Laki- laki

$29(34,1)$

- Perempuan

$56(65,9)^{*}$

Status Pernikahan

- Tidak menikah

- Menikah

$81(95,3)^{*}$

Pendidikan

- Tidak sekolah

$5(5,9)$

- SD

$30(35,3)^{*}$

- SMP

$15(17,6)$

- SMA

$26(30,6)$

- Sarjana

$5(5,9)$

- Lainnya

$4(4,7)$

Pekerjaan

- Bekerja

- Tidak bekerja

$51(60)^{*}$

Depresi

- Tidak depresi

$31(36,5)$

- Depresi

$54(63,5)^{*}$

-Depresi ringan

11(20,4)

-Depresi sedang

13(24)

-Depresi berat

$11(20,4)$

-Depresi sangat berat

19(35,2)*

Cemas

- Tidak Cemas

$18(21,2)$

- Cemas

$67(78,8) *$

-Cemas ringan

$5(7,5)$

-Cemas sedang

$20(29,9)$

-Cemas berat

$11(16,4)$

-Cemas sangat berat

$31(46,2)^{*}$

Stres

- Tidak stres

$25(29,4)$

- Stres

$60(70,6) *$

-Stres ringan

$10(16.6)$

-Stres sedang

$16(26,7)$

-Stres berat

$18(30)^{*}$

-Stres sangat berat

$16(26,7)$ 
Tabel 2. Gambaran intensitas nyeri berdasarkan faktor demografi pada penderita nyeri neuromuskuloskeletal kronis

\begin{tabular}{|c|c|c|c|c|c|}
\hline & & \multicolumn{2}{|l|}{ IN1 } & \multicolumn{2}{|l|}{ IN2 } \\
\hline & & Tolerable pain & Intolerable pain & Tolerable pain & Intolerable pain \\
\hline \multirow[t]{2}{*}{ Usia } & $<60$ tahun & $2(2,4)$ & $57(67,1)^{*}$ & $19(22,4)$ & $40(47,1)^{*}$ \\
\hline & $\geq 60$ tahun & $6(7,1)$ & $20(23,5)$ & $12(14,1)$ & $14(16,5)$ \\
\hline Jenis & Laki - laki & $3(3,5)$ & $26(30,6)$ & $12(14,1)$ & $17(20)$ \\
\hline kelamin & Perempuan & $5(5,9)$ & $51(60)^{*}$ & $19(22,4)$ & $37(43,5)^{*}$ \\
\hline \multirow[t]{3}{*}{ Status } & $\begin{array}{l}\text { Belum } \\
\text { menikah }\end{array}$ & $0(0)$ & $4(4,7)$ & $1(1,2)$ & $3(3,5)$ \\
\hline & Menikah & $8(9,4)$ & $73(85,9) *$ & $30(35,3)$ & $51(60)^{*}$ \\
\hline & & & abel 2. Lanjutan & & \\
\hline \multirow[t]{2}{*}{ Pendidikan } & Rendah & $2(2,4)$ & $48(56,5)^{*}$ & $19(22,4)$ & $31(36,5)^{*}$ \\
\hline & Tinggi & $6(7,1)$ & $29(34,1)$ & $12(14,1)$ & $23(27,1)$ \\
\hline \multirow[t]{2}{*}{ Pekerjaan } & Bekerja & $2(2,4)$ & $32(37,6)$ & $9(10,6)$ & $25(29,4)$ \\
\hline & $\begin{array}{l}\text { Tidak } \\
\text { bekerja }\end{array}$ & $6(7,1)$ & $45(52,9)^{*}$ & $22(25,9)$ & $29(34,1) *$ \\
\hline
\end{tabular}

*Persentase terbanyak

Keterangan: IN1: Nyeri saat ini; IN2: Nyeri rata - rata dalam 1 minggu

Tabel 3. Hubungan antara depresi, cemas, dan stres dengan faktor demografi pada penderita nyeri neuromuskuloskeletal kronis

\begin{tabular}{lccccccccc}
\hline & \multicolumn{3}{c}{ Cemas } & \multicolumn{3}{c}{ Depresi } & \multicolumn{3}{c}{ Stres } \\
\cline { 2 - 10 } & RO & $\mathbf{9 5 \%}$ IK & p & RO & $\mathbf{9 5 \% ~ I K ~}$ & p & RO & 95\% IK & p \\
\hline Usia & 3,67 & $1,39-9,64$ & $0,01^{*}$ & 2,94 & $1,00-8,62$ & $0,04 *$ & 1,83 & $0,69-4,90$ & 0,22 \\
Jenis kelamin & 1,14 & $0,45-2,91$ & $0.78^{*}$ & 1,45 & $0,46-0,56$ & 0,52 & 1,14 & $0,42-3,09$ & 0,79 \\
Status & 1,79 & $0,24-13,41$ & 0,62 & 1,79 & $1,14-1,44$ & 0,57 & 1,45 & $1,25-1,67$ & 0,32 \\
Pendidikan & 0,51 & $0,21-1,25$ & 0,14 & 0,36 & $0,12-1,04$ & 0,05 & 0,42 & $0,16-1,10$ & 0,07 \\
Pekerjaan & 0,92 & $0,37-2,27$ & 0,85 & 0,94 & $0,33-2,74$ & 0,91 & 0,79 & $0,30-2,07$ & 0,63 \\
\hline
\end{tabular}

*Hubungan bermakna $(\mathrm{p}<0,05)$

Tabel 4. Hubungan antara intensitas nyeri dengan depresi, cemas, dan stres pada penderita nyeri neuromuskuloskeletal kronis

\begin{tabular}{|c|c|c|c|c|c|c|c|c|c|}
\hline & \multicolumn{3}{|c|}{ Cemas } & \multicolumn{3}{|c|}{ Depresi } & \multicolumn{3}{|c|}{ Stres } \\
\hline & RO & $95 \%$ IK & p & RO & $95 \%$ IK & $\mathrm{p}$ & RO & $95 \%$ IK & $\mathrm{p}$ \\
\hline IN1 & 15,4 & $1,80-132,72$ & $0,00 *$ & 42 & $4,70-375,41$ & $0,00 *$ & 4,75 & $1,04-21,70$ & $0,04 *$ \\
\hline IN2 & 1,16 & $0,47-2,90$ & 0,75 & 3,69 & $1,25-10,90$ & $0,01 *$ & 1,24 & $0,47-3,23$ & 0,66 \\
\hline
\end{tabular}

*Hubungan bermakna $(\mathrm{p}<0,005)$

Keterangan: IN1: Nyeri saat ini; IN2: Nyeri rata-rata dalam 1 minggu

\section{Pembahasan}

Hasil penelitian ini hampir serupa dengan hasil penelitian Oliveira (2014) pada pasien nyeri punggung kronik dengan usia $22-91$ tahun, $63 \%$ berusia $<60$ tahun, rata - rata usia 54,8, 61,6\% menikah, $61,6 \%$ pendidikan SD, $80 \%$ bekerja. $^{12}$ Penelitian tersebut mencantumkan secara mendetil jenis pekerjaan subjek pada penelitiannya, sedangkan pada penelitian ini hanya dibagi atas bekerja dan tidak bekerja. Penelitian Shinsuke (2015) di Jepang tentang prevalensi, karakteristik dan dampak nyeri kronis terhadap kualitas hidup pada subjek berusia 20 - 99 tahun, didapatkan $57,4 \%$ usia $\geq 60$ tahun, $60,7 \%$ perempuan, $89,3 \%$ berkeluarga, $60 \%$ tidak bekerja. ${ }^{13}$ Shinsuke (2015) 
memiliki hasil penelitian bahwa pada penderita nyeri kronis terbanyak adalah $>60$ tahun, yang merupakan hasil yang berbeda dengan penelitian ini, hal ini dikarenakan subjek yang lebih banyak berusia $>60$ tahun.

Hasil penelitian ini menunjukkan prevalensi depresi, kecemasan, dan stres yang tinggi. Penelitian Britt (2011) pada 160 penderita nyeri kronis 47,1\% mengalami depresi, 45,8\% mengalami cemas dengan alat ukur HAD (Hospital Anxiety and Depression), dan 48,1 mengalami stres sedang hingga berat dengan alat ukur IES (Impact of Event Scale)..$^{14}$ Penelitian ini juga menunjukan mayoritas responden mengalami tingkat depresi, tingkat cemas, dan tingkat stres sangat berat. Penelitian Rice (2015) pada penderita nyeri kronis dengan kuesioner DASS menunjukan 28,1\% depresi sedang, $38,3 \%$ cemas sangat berat, dan 18,6\% stres sedang. ${ }^{15}$ Penelitian Britt (2011) dan Rice (2015) sesuai dengan penelitian ini. Kedua penelitian tersebut mengkelompokan setiap gangguan psikologi ke dalam tingkat ringan hingga berat. Penelitian Britt (2011) menunjukan bahwa pada penderita dengan nyeri kronis, angka depresi, cemas, dan stres lebih tinggi dibanding yang tidak mengalami nyeri kronis. Kondisi tersebut dapat mengganggu aktivitas sehari - hari dan mengurangi kualitas hidup penderita.

Kedua item intensitas nyeri menunjukan bahwa intensitas nyeri yang umum dirasakan penderita nyeri neuromuskuloskeletal kronis berada pada kelompok intolerable pain. Hal ini sesuai dengan penelitian Breivik et al (2006) di Eropa bahwa sekitar $18-50 \%$ pasien nyeri kronis mengalami intensitas nyeri yang berat. ${ }^{16}$

Boggero (2015) menyatakan pada usia muda lebih berisiko mengalami nyeri sedangkan orang tua lebih dapat menerima nyerinya dan lebih dapat mengontrol emosinya dibanding usia muda. Koping mental pada orang tua lebih baik dibandingkan pada usia muda, orang tua lebih termotivasi untuk menambah pengalaman positif, dan lebih menikmati kehidupannya. ${ }^{17}$

Nyeri kronis banyak diderita oleh perempuan. Louis (2012) menyatakan bahwa respon nyeri pada perempuan lebih sensitif pada pria. Sistem opioid endogen berkaitan dengan regulasi hormon pada tubuh manusia. Perempuan memiliki kadar testosteron yang lebih rendah dibandingkan pria. ${ }^{18}$ Craft (2007) menyatakan testosteron berfungsi sebagai antinosiseptor dan hormon proteksi. ${ }^{19}$

Reese (2010) menyatakan bahwa pada penderita yang sudah menikah memiliki tingkat nyeri yang lebih tinggi. Nyeri kronis mengganggu aktivitas sehari-hari penderita, dan tidak dapat bekerja dengan baik, sehingga berdampak lanjut terhadap gangguan mental emosional (depresi, cemas, dan stres). Dukungan pasangan juga berdampak pada penderita nyeri kronis, dukungan pasangan yang buruk akan memperburuk distres psikologi penderita, sehingga membuat intensitas nyeri penderita semakin tinggi. ${ }^{20}$

Penelitian Antony (2016) tentang pengaruh faktor demografi terhadap intensitas nyeri pada penderita nyeri kronis yang dirawat di nursing care didapatkan rerata usia 64,1 tahun, $10 \%$ perempuan, $16,8 \%$ tidak lulus pendidikan tinggi. ${ }^{21}$ Penelitian Baker (2008) tentang pengaruh intensitas nyeri pada pasien perempuan berkulit hitam yang menderita nyeri kronis, didapatkan rata - rata usia 71,1 tahun dijumpai 40\% menderita LBP dengan intensitas nyeri 29,02 yang diukur dengan Pain Rating Index (PRI).22

Hasil uji chi square menunjukan bahwa terdapat hubungan bermakna antara usia dengan depresi. ${ }^{23}$ Penelitian Park (2016) sesuai dengan penelitian ini bahwa peran sosiodemografi pada penderita nyeri kronis sering ditemui pada usia yang lebih tua. Tidak ada hubungan bermakna antara depresi dengan jenis kelamin $(\mathrm{p}=0,78)$; status pernikahan $(\mathrm{p}=0,62)$; tingkat pendidikan $(\mathrm{p}=0,14)$; pekerjaan $(\mathrm{p}=0,85)$ pada penelitian ini. Hal ini sesuai dengan penelitian Sofia (2008) bahwa tidak ada hubungan antara jenis kelamin dengan depresi pada penderita nyeri kronis dengan kuesioner Hospital Anxiety and Depression Scale - Depression (HAD-D). Perempuan memiliki prevalensi yang lebih tinggi dalam depresi dibanding pria meskipun hubungannya tidak bermakna. ${ }^{14,24}$

Hasil uji chi square menunjukan bahwa terdapat hubungan bermakna antara cemas dengan usia. Tidak ada hubungan bermakna antara cemas dengan tingkat pendidikan, jenis kelamin, status pernikahan, dan pekerjaan. Hal ini sesuai dengan penelitian yang dilakukan oleh Sofia (2008) bahwa tidak ada hubungan antara jenis kelamin dengan 
cemas pada penderita nyeri kronis. Hal ini sesuai dengan penelitian Park (2016) dan Sofia (2008) yang mendukung bahwa usia dan cemas memiliki hubungan bermakna. Temuan Boggero (2015) sesuai dengan penelitian ini bahwa pada usia muda lebih rentan terkena nyeri karena orang yang lebih tua biasanya lebih dapat menerima nyeri dan dapat mengendalikan emosi dengan lebih baik dibanding usia muda. Hal ini berbeda dengan Sang (2016) yang menyatakan bahwa orang dengan usia yang lebih tua rentan mengalami nyeri karena sering terkena hyperalgesia. ${ }^{17,25}$ Hal ini diakibatkan berkurangnya toleransi nyeri dan efektifitas dari analgetika endogen sehingga membuat orang yang berusia lebih tua lebih sulit mengatasi nyerinya. Temuan Shin (2017) pada perempuan lebih banyak mengalami nyeri dan masalah mental dibandingkan pria, hal ini dikaitkan dengan perempuan yang lebih sensitif dan lebih rentan dengan masalah mental. ${ }^{26}$ Tidak terdapat hubungan bermakna antara stres pada penderita nyeri neuromuskuloskeletal kronis dengan usia, jenis kelamin, status pernikahan, tingkat pendidikan, dan jenis pekerjaan. Hal ini sesuai dengan penelitian Sofia (2008) bahwa tidak ada hubungan antara jenis kelamin dengan stres pada penderita nyeri kronis dengan kuesioner IES (The Impact of Event Scale).

Hasil uji chi square menunjukan bahwa terdapat hubungan bermakna antara IN1 dengan depresi pada penderita nyeri neuromuskuloskeletal kronis, sedangkan IN2tidak bermakna. Hal ini sesuai dengan penelitian Sofia (2008) yang menunjukan ada korelasi antara intersitas nyeri yang diukur dengan cara VAS (Visual Analog Scale) dengan depresi $(r=0,252, p=0,00) .{ }^{24}$ Penelitian Maria (2013) tentang intensitas nyeri pada penderita nyeri kronis menunjukkan bahwa terdapat hubungan yang bermakna antara intensitas nyeri dengan depresi $\quad\left(R^{2}=0,09, p<0.00\right) .{ }^{27} \quad$ Hasil penelitian Oliveira (2014) juga menunjukan adanya korelasi antara intensitas nyeri dengan depresi $(0,166) .{ }^{12}$

Menurut Oliviera (2014) dan Sang (2016) depresi berkaitan dengan intensitas nyeri, semakin berat intensitas nyeri yang dirasakan oleh penderita maka juga akan semakin berat depresi yang dialami penderita. ${ }^{12,28}$ Menurut Thorn (2010) depresi berkaitan dengan nyeri yang dirasakan oleh penderita nyeri kronis, dan membuatnya terganggu dalam menjalani aktivitas sehari-hari. Hal ini diakibatkan oleh nyeri yang terus menerus dan berdampak pada berkurangnya kualitas hidup..$^{29}$

Hasil uji chi square menunjukan bahwa terdapat hubungan bermakna antara IN1 dan IN2 dengan cemas pada penderita nyeri neuromuskuloskeletal kronis. Hal ini sesuai dengan penelitian Sofia (2008) yang menunjukan adanya korelasi antara intersitas nyeri dengan cemas $(\mathrm{r}=0,186, \mathrm{p}=$ 0,02). ${ }^{24}$ Penelitian Maria (2013) menunjukan adanya hubungan intensitas nyeri dengan cemas $\left(R^{2}=0,07, p<0,00\right) .{ }^{27}$ Hasil penelitian Martha (2009) intensitas nyeri terdapat hubungan dengan cemas $(p=0,03) .^{30}$

Penelitian Sulaiman (2017) membuktikan bahwa pasien yang mendapatkan perawatan di Pain Clinic memiliki prevalensi cemas yang tinggi. Hal tersebut meningkat sesuai dengan intensitas nyeri. Intensitas nyeri yang tinggi menyebabkan cemas semakin berat. ${ }^{31}$ Gejala depresi dan cemas berpengaruh pada intensitas pada pasien nyeri, semakin tinggi intensitas nyeri maka semakin berisiko pasien tersebut mengalami depresi dan cemas. ${ }^{32}$

Intensitas nyeri dan depresi, cemas, maupun stres memiliki hubungan bermakna, terutama pada cemas yang memiliki hubungan yang erat dengan intensitas nyeri. ${ }^{29}$ Nyeri dapat membuat pasien menjadi takut dan menghindari rasa nyeri, yang kemudian membuat pasien menjadi sulit mengendalikan diri. Hal ini kemudian akan memunculkan gejala fisik cemas seperti palpitasi dan pernafasan yang dangkal. Saat nyeri menjadi kronis pasien juga akan merasakan intesitas nyeri yang semakin tinggi karena adanya hipersensitivitas sampai terjadinya catastrophizing. Cemas yang menjadi semakin berat dan sulit diatasi mempengaruhi strategi coping yang membuat penderita cenderung berusaha menghindari nyeri. ${ }^{33}$ Cemas sering timbul pada penderita nyeri kronis, karena nyeri merupakan sinyal berbahaya, yang akan direspon oleh tubuh dengan fight or flight respons. ${ }^{34}$

Hasil uji chi square menunjukan bahwa terdapat hubungan bermakna antara IN1 dengan stres pada penderita nyeri neuromuskuloskeletal kronis. Hal ini sesuai dengan penelitian Sofia (2008) yang menunjukan adanya korelasi antara intersitas nyeri dengan stres $(r=0,183, p=0,02) .^{24}$ Ruth (2011) 
menemukan bahwa intensitas nyeri dan masalah mental memiliki hubungan bermakna. Hal ini juga dipengaruhi oleh frekuensi dari nyeri, dampak dari nyeri yang mengganggu kegiatan sehari-hari, dan respon emosional pasien terhadap nyeri. ${ }^{35}$

Penelitian ini menemukan bahwa kedua item intensitas nyeri (IN1 dan IN2). Nyeri memengaruhi

\section{Simpulan}

Terdapat hubungan antara intensitas nyeri dengan depresi, cemas, dan stres pada pasien nyeri neuromuskuloskeletal kronis di Rumah Sakit Atma Jaya.

\section{Daftar Rujukan}

1. Treede R-D, Rief W, Barke A, Aziz Q, Bennett MI, Benoliel R, et al. A classification of chronic pain for ICD-11. Pain. 2015;156(6):1003-7

2. Davison MJ, Ioannidis G, Maly MR, Adachi JD, Beattie KA. Intermittent and constant pain and physical function or performance in men and women with knee osteoarthritis: data from the osteoarthritis initiative. Clin Rheumatol. 2016;35(2):371-9.

3. Goldberg DS, McGee SJ. Pain as a global public health priority. BMC Public Health. 2011;11:770

4. MicroRNAs as modulators and biomarkers of inflammatory and neuropathic pain conditions ClinicalKey; Neurobiology of disease. 2014;71:159-168

5. Fayaz A, Croft P, Langford RM, Donaldson LJ, Jones GT. Prevalence of chronic pain in the UK: a systematic review and meta-analysis of population studies. BMJ Open. 2016 ;6(6):e010364.

6. World Health Organization. Depression and other common mental disorders. Global Health Estimates. Geneva: 2017. Licence: CC BYNC-SA 3.0 IGO.

7. Rayner L, Hotopf M, Petkova H, Matcham F, Simpson A, McCracken LM. Depression in patients with chronic pain attending a specialised pain treatment centre: prevalence and impact on health care costs. Pain. 2016;157(7):1472-9. keadaan psikologis pasien karena mengganggu keseimbangan neurotransmitter yang menyebabkan terjadinya gangguan mood. Timbulnya cemas sering berupa akibat nyeri kronis, berkaitan dengan intensitasnya, sementara depresi umumnya lebih banyak terjadi sebagai komorbiditas yang mendahului nyeri. ${ }^{12,28,31,32}$

\section{Pengakuan}

Terima kasih kepada semua staff Departemen Saraf Fakultas Kedokteran Universitas Atma Jaya, terutama kepada dr. Cynthia Tjitra.

8. Wong WS, Chen PP, Yap J, Mak KH, Tam BKH, Fielding R. Chronic pain and psychiatric morbidity: a comparison between patients attending specialist orthopedics clinic and multidisciplinary pain clinic. Pain Med Malden Mass. 2011;12(2):246-59.

9. Guruprasad S, S RK, Shah P. Prevalence of depression, anxiety, and stressin patients with mechanical low back pain. Int J Ther Rehabil Res. 2015;4(4):67-72.

10. Nicholson B, Verma S. Comorbidities in chronic neuropathic pain. Pain Med Malden Mass. 2004;5 Suppl 1:S9-27.

11. DeHeer EW, Gerrits MMJG, Beekman ATF, Dekker J, van Marwijk HWJ, de Waal MWM, et al. The association of depression and anxiety with pain: a study from NESDA. PloS One. 2014;9(10):e106907.

12. Garbi M de OSS, Hortense P, Gomez RRF, da Silva T de CR, Castanho ACF, Sousa FAEF. Pain intensity, disability and depression in individuals with chronic back pain. Rev Lat Am Enfermagem. 2014;22(4):569-75.

13. Inoue S, Kobayashi F, Nishihara M, Arai Y$\mathrm{CP}$, Ikemoto T, Kawai T, et al. Chronic pain in the japanese community-prevalence, characteristics and impact on quality of life. PLoS ONE . 2015;10(6).

14. Stalnacke B-M. Life satisfaction in patients with chronic pain - relation to pain intensity, disability, and psychological factors. Neuropsychiatr Dis Treat. 2011;7:683-9. 
15. Rice D, Mehta S, Shapiro A, Pope J, Harth M, Morley-Forster P, et al. Psychological distress in out-patients assessed for chronic pain compared to those with rheumatoid arthritis. Pain Research \& Management ;2016;7071907.

16. Breivik H, Collett B, Ventafridda V, Cohen R, Gallacher D. Survey of chronic pain in Europe: prevalence, impact on daily life, and treatment. Eur J Pain Lond Engl. 2006;10(4):287-333.

17. Boggero IA, Geiger PJ, Segerstrom SC, Carlson CR. Pain intensity moderates the relationship between age and pain interference in chronic orofacial pain patients Exp Aging Res. 2015;41(4):463-74.

18. Barnabe C, Bessette L, Flanagan C, Leclercq S, Steiman A, Kalache F, et al. Sex differences in pain scores and localization in inflammatory arthritis: a systematic review and metaanalysis. J Rheumatol. 2012;39(6):1221-30.

19. Craft RM. Modulation of pain by estrogens. Pain. 2007 Nov;132 Suppl 1:S3-12

20. Reese JB, Somers TJ, Keefe FJ, MosleyWilliams A, Lumley MA. Pain and functioning of rheumatoid arthritis patients based on marital status: is a distressed marriage preferable to no marriage? J Pain Off J Am Pain Soc. 2010;11(10):958-64.

21. Antony T, Merghani TH. The influence of demographic and psychosocial factors on the intensity of pain among chronic patients receiving home-based nursing care. Indian $\mathrm{J}$ Palliat Care. 2016;22(3):362-5.

22. Baker TA, Buchanan NT, Corson N. Factors influencing chronic pain intensity in older black women: examining depression, locus of control, and physical health. J Womens Health. 2008;17(5):869.

23. Wang H-Y, Fu T-S, Hsu S-C, Hung C-I. Association of depression with sleep quality might be greater than that of pain intensity among outpatients with chronic low back pain. Neuropsychiatr Dis Treat. 2016;12:1993-8.

24. Ahman S, Stalnacke B-M. Post-traumatic stress, depression, and anxiety in patients with injury-related chronic pain: A pilot study. Neuropsychiatr Dis Treat. 2008;4(6):1245-9.

25. Park SJ, Yoon DM, Yoon KB, Moon JA, Kim SH. Factors associated with higher reported pain levels in patients with chronic musculoskeletal pain: a cross-sectional, correlational analysis., factors associated with higher reported pain levels in patients with chronic musculoskeletal pain: a cross-sectional, Correlational Analysis. PLoS ONE PLoS ONE. 2016;11, 11(9, 9).

26. Shin SM. Prevalence and trends of pain associated with chronic diseases and personal out-of-pocket medical expenditures in Korea. Korean J Pain. 2017;30(2):142-50.

27. Bromley Milton M, Börsbo B, Rovner G, Lundgren-Nilsson $\AA$, Stibrant-Sunnerhagen K, Gerdle B. Is pain intensity really that important to assess in chronic pain patients? a study based on the swedish quality registry for pain rehabilitation (SQRP). PLoS ONE 2013;8(6).

28. Park SJ, Yoon DM, Yoon KB, Moon JA, Kim SH. Factors associated with higher reported pain levels in patients with chronic musculoskeletal pain: a cross-sectional, correlational analysis., factors associated with higher reported pain levels in patients with chronic musculoskeletal pain: a cross-sectional, Correlational Analysis. PLoS ONE PLoS ONE. 2016;11, 11(9, 9).

29. Day MA, Thorn BE. The relationship of demographic and psychosocial variables to pain-related outcomes in a rural chronic pain population. Pain. 2010;151(2):467-74.

30. Martha M. C. Castro, Lucas C. Quarantini, Carla Daltro, Milke Pires-Caldas, Karestan C. Koenen, Irismar R. de Oliveira et al. Comorbid depression and anxiety symptoms in chronic pain patients and their impact on health-related quality of life. 2011;38(4):126-931.

31. Elbinoune I, Amine B, Shyen S, Gueddari S, Abouqal R, Hajjaj-Hassouni N. Chronic neck pain and anxiety-depression: prevalence and associated risk factors. Pan Afr Med J. 2016;24.

32. Sulaiman W, Zanyuin NM, Kheong MK, Bhojwani KM, Seung OP. Chronic pain with anxiety and depression: a comparison between patients attending multidisciplinary pain and rheumatology clinic. Biomed Res. 2017;28(1). 
33. Brede E, Mayer TG, Neblett R, Williams M, Gatchel RJ. The Pain Anxiety Symptoms Scale fails to discriminate pain or anxiety in a chronic disabling occupational musculoskeletal disorder population. Pain Pract Off J World Inst Pain. 2011;11(5):430-8.
34. ISP. What is Anxiety? Institute for Chronic Pain. Anxiety Pain.2015 (Available at: https://www.instituteforchronicpain.org/underst anding-chronic-pain/complications/anxiety).

35. Ruscheweyh R, Nees F, Marziniak M, Evers S, Flor $\mathrm{H}$, Knecht S. Pain catastrophizing and pain-related emotions: influence of age and type of pain. Clin J Pain. 2011;27(7):578-8 